\title{
A Study to Assess the Effectiveness of Structured Training Programme on Knowledge Regarding Quality Concepts among Nursing Officers at Base Hospital, Kalmunai(North),Sri lanka
}

\author{
Dr. R. Muraleeeswaran ${ }^{1}$, Dr. M. Thenuka ${ }^{2}$ \\ ${ }^{1}$ Medical Superintendent, Base Hospital Kalmunai( North).Sri Lanka \\ ${ }^{2}$ Dental surgeon, Divisional hospital, Santhiveli, Sri lanka
}

\begin{abstract}
Nursing officers are directly involved in patient care services. Therefore their knowledge on quality concepts is very important for overall improvement of health care services in Sri Lanka. Improving the quality of health care has become a concern for patients, governments, managers, and professionals working in low-income countries. Quality of Health care is defined as the degree to which health services for individuals and populations increased the likelihood of desired health outcomes and are consistent with current professional knowledge. Therefore, a quasi-experimental study to assess the effectiveness of structured teaching programme was used to assess knowledge of nursing officers regarding quality concepts . One group pre-test post-test design was used for this study. Convenient sampling technique is used on the sample for the present study consists of 100 nursing officers from base hospital kalmunai(north),Sri lanka.Self-administered Knowledge questionnaires (Pretest - Posttest) were administered. The collected data were analyzed by using descriptive \& inferential statistics based on predefined objectives of the study. Present study shows that pre test knowledge level of nursing officers was significantly $(P<0.05)$ less towards Quality concepts. Study reveals that proper education $(S T P)$ enhancespost test knowledge among nursing officers regarding quality concepts.
\end{abstract}

Keywords: quality concepts, nursing officers, Knowledge, Structured training programme

\section{Introduction}

Quality of Health care is defined as -thedegree to which health services for individuals and populations increased the likelihood of desired health outcomes and are consistent with current professional knowledge" (IOM 1990).

Health is defined as —astate of complete physical, mental and social wellbeing and not merely the absence of diseases or infirmity" (world Health Organization 1978). To keep the nation healthy, the government needs to deliver health care services in good quality to its citizens. The state health care service structures differ in different countries. Broadly these services can be categorized into two group: curative and preventive services. The curative services concentrate on curative aspects which include both out - patients care. The preventive aspects mainly rely on keeping the public healthy and preventing them from becoming tnhealthy".

There are gross disparities in the provision of health care between and within countries, existing among rich and poor, urban and rural. As the health of the majority of the rural poor is unacceptably low there was great dissatisfaction in meeting people's basic health needs. The need to search for and promote an effective system that would provide comprehensive health care for all, gave rise to - Healthfor all by the Year 2000" (Park 1995). The basic principle underlying this concept is for all the people to have an opportunity enjoy good health,For successful Implementation of a quality programme, it is important for all categories of staff to have a good knowledge and skills in implementing a quality programme. It is known that however much improve the knowledge, without correct attitudes there may not be an improvement in practices. Therefore, to improve the good practices in quality it is important for all the staff to have a good knowledge, and attitudes towards quality concepts.

Nursing officers are directly involved in patient care services. Therefore their knowledge on quality concepts are very important for overall improvement of health care services in Sri Lanka.Improving the quality of health care has become a concern for patients, governments, managers, and professionals working in low-income countries, where many people do not have access to services, Patients with money, on the other hand, are paying more for their care, both for public and private services, but they often do not experience any Improvements in health or service quality. Patients increasingly expect more from health care services and compare their experience with those countries with higher quality, Accessible, quality health care is one determinant of a nation's health, which has been linked directly to national wealth (World Health Organization 2004a) This theory cannot be applied to the government health care services, as it can be the only place to provide services to the most vulnerable and low social class citizens, On the other hand still people believe that more skilled and knowledgeable people are working in the government sector. Therefore in an emergency and for the critical care, the majority of population in the country is still believed that government hospitals are better. As there are limited choices, they do not complain but do come though not satisfied with the quality of services So we have to pay much more attention to improve the quality of services and responsiveness. 


\section{International Journal of Science and Research (IJSR) \\ ISSN (Online): 2319-7064 \\ Index Copernicus Value (2013): 6.14 | Impact Factor (2015): 6.391}

The Ministry of Healthcare and Nutrition by General Circular No 01.29.2009 (Ministry of Healthcare \& Nutrition, 2009) has directed all hospitals to initiate productivity and quality improvement programmes, This was enhanced with the instruction given by the General Circular No 02$109 / 2003$ and dated $08^{\text {th }}$ October 2003. It is pleased to note that some of our hospitals and other health institutions have initiated productivity and quality improvement programme as per instruction given by the above mentioned circulars.

The Ministry of Healthcare and Nutrition has decided to expand the quality assurance programme to all health institutions in Sri Lanka, in order to improve the quality and safety of health care services.

\section{Statement of the Problem}

—AStudy to Assess the Effectiveness of Structured Training Programme on Knowledge among nursing officers regarding quality concepts at base hospital kalmunai(north),Sri lanka

\section{Objectives}

1) To assess the level of knowledge regarding quality concepts amongnursing officers at base hospital kalmunai(north)

2) To evaluate the effectiveness of structured training programme on quality concepts amongnursing officers at base hospital kalmunai(north) .

3) To find association between post test knowledge scores of quality concepts amongnursing officers with selected demographic variables.

\section{Hypothesis:}

H01 :- There will be statistically no significant relationship between the score obtained on the level of knowledge regarding quality concepts among nursing officers at base hospital kalmunai(north).

H02- There will be statistically no significant relationship between selected socio demographic variables \& score obtained on level of knowledge regarding quality concepts amongnursing officers at base hospital kalmunai(north).

\section{Hypothesis}

H01 :- There will be statistically no significant relationship between the score obtained on the level of knowledge regarding quality concepts among nursing officers at base hospital kalmunai(north).

H02- There will be statistically no significant relationship between selected socio demographic variables \& score obtained on level of knowledge regarding quality concepts amongnursing officers at base hospital kalmunai(north).

\section{Materials \& Methods}

Research approach \& design: quasi experimental one group pre- test, post- test design, to measure The Effectiveness of Structured Training Programme.

$\mathrm{O} 1 \rightarrow \mathrm{X} \rightarrow \mathrm{O} 2$
Pre-test Intervention Post-test

Figure 1: Schematic representation of one group pre-test post-test research design.

Sample and sampling technique: Convenient sampling technique is used on the sample for the present study consists of 100nursing officers at base hospital kalmunai(north)

Tool: The self structured questionnaire was prepared which consists of three parts.

Part I: Demographic Proforma: Consists of 07 items of socio demographic data which includes information of respondents about Age, Gender, Religion, Education, Source of Information, Habitant and Types of family of adolescents.

Part II: Knowledge questionnaire : Consists of 20 items of objectives type related to knowledge of nursing officers at base hospital kalmunai(north)regarding Awareness of Nursing Officers on Quality concepts, Understanding on contents of quality concepts, Relevant activities needed to maintain the Standards of service quality. Overall assessment of knowledge in relation to Correct identification of activities needed to maintain The service quality. All the items were scored as the each correct answer was given a score of ${ }^{1}{ }^{\text {‘ }}$ and wrong answers a score of ${ }^{0}{ }^{*}$.

\section{Conceptual Framework}

Maiman and Becker's Health Belief Model is used for framing the concept of the present study on the effectiveness of structured teaching programme regarding knowledge regarding quality concepts among nursing officers at base hospital kalmunai(north). This conceptual frame work provides a way that how people will react in relation to health care. This model proposes that people will not attempt to adopt the preventive practices unless the disease is not threatening to some aspect of their lives.

\section{Data Collection Method \& Ethical Consideration}

The data collection procedure was carried out from $5^{\text {th }}$ of may 2014 to $5^{\text {th }}$ of may 2015. Formal written permission obtained. The investigator took consent from the nursing officers at base hospital kalmunai(north). Confidentiality was maintained during data collection. The average time taken was 45 minutes. After an interval of seven days, the post test was administered by using the same knowledge questionnaire to evaluate the effectiveness of Structured Training Programme respectively.

Data analysis: The obtained data will be analyzed in terms of the objectives and hypothesis of the study by both descriptive and inferential statistics. The mean post test scores (33.45\%) was higher than the mean pre test scores $(9.84 \%)$ with $\mathrm{t}^{\mathrm{t}}$ value $(\mathrm{t}=21.4532)$ being significant at $\mathrm{p}$ $0.001 \%$ level on the finding of the data indicates that this study was feasible \& enhance the knowledge regarding quality concepts among nursing officers at base hospital kalmunai(north). 


\section{International Journal of Science and Research (IJSR) ISSN (Online): 2319-7064 \\ Index Copernicus Value (2013): 6.14 | Impact Factor (2015): 6.391}

\section{Result}

\section{Section I: Description of demographic data}

Age of all participants was 23-60 years, 25\% participants were male and $75 \%$ were female, Majority of them $87 \%$ were Hindus, Most of them $78 \%$ participants were living in urban area.Most of the participants that is $69 \%$ belonged to nuclear family and 31\% belonged to joint family, Majority of them $74 \%$ participants had personal source of information.

Section II: Distribution of knowledge regarding quality concepts among nursing officers at base hospital kalmunai(north).

Table 1: Assessment of level of knowledge of adolescents on substance abuse in pre \&post test:

$$
\mathrm{N}=100
$$

\begin{tabular}{|c|c|c|c|c|}
\hline \multirow{2}{*}{ Level of knowledge } & \multicolumn{2}{|c|}{ Pre test } & \multicolumn{2}{c|}{ Post test } \\
\cline { 2 - 5 } & Frequency & $\%$ & Frequency & $\%$ \\
\hline Adequate knowledge (>75 \%) & 16 & 16 & 66 & 66 \\
\hline $\begin{array}{c}\text { Average knowledge } \\
(50-75 \%)\end{array}$ & 14 & 14 & 29 & 29 \\
\hline $\begin{array}{c}\text { Inadequate knowledge } \\
(<50 \%)\end{array}$ & 70 & 70 & 5 & 5 \\
\hline
\end{tabular}

In relation to the knowledge of the pre -test only $16 \%$ of the subjects had adequate knowledge, where as in post test knowledge score reveled that majority of them had [66\%] adequate knowledge regarding regarding quality concepts among nursing officers.

Section III: Distribution to evaluate the effectiveness of structured teaching programme on adolescent's substance abuse. $\mathrm{N}=100$

\begin{tabular}{|l|c|c|c|c|c|c|}
\hline \multirow{2}{*}{ DOMAIN } & \multicolumn{2}{|c|}{ Pre test } & \multicolumn{2}{c|}{ Post test } & Improvement & \multirow{2}{*}{$\mathrm{t}$ - test } \\
\cline { 2 - 6 } & MEAN & SD & Mean & SD & Mean & \\
\hline Knowledge & 9.84 & 4.2 & 33.45 & 6.4 & 11.65 & $\mathrm{t}=21.4532$ \\
\hline
\end{tabular}

$\mathrm{P}>0.0001$ (extremely statistically significant)

The obtained post test mean value 33.45 is higher than the pre test 9.84. The improvement between pre-test and posttest was 23.61and obtained paired $\mathrm{t}^{\mathrm{t}}$ test value was21.4532, it is highly significant at $1 \%$ level $\mathrm{p}>0.001$. Hence it is inferred that there is significant increase in the knowledge level of the adolescents regarding quality concepts among nursing officers at base hospital kalmunai(north).

Section IV: Determine the association between pre-test knowledge scores of regarding quality concepts among nursing officers at base hospital kalmunai(north).

There was the significant association between post test knowledge scores and selected variables like age, sex, year of education ( $\mathrm{P}>0.01)$, types of family ( $\mathrm{P}>0.05$ level), but there was no significant association between post test knowledge score and source of information,reigion\& area of residence.

\section{Conclusion}

The study found that the planned training programme was highly effective and successful. The study aimed at assessing the effectiveness of structured training programme on knowledge regarding quality concepts among nursing officers at base hospital kalmunai(north),srilanka.Results of this studyempahasize on inclusion of training programs regarding quality concepts among nursing officers in the hospitals of srilanka.so that the quality of health care will be improved.

\section{References}

[1] 1L. H. Aiken, S. P. Clarke, D. M. Sloane, and J. H. Silber, Education Levels of Hospital Nurses and Surgical Patient Mortality." Journal of the American Medical Association 290 (Sept. 24, 2003): 1617-23; and L. H. Aiken, S. P. Clarke, D. M. Sloane, J. Sochalski, and J. H. Silber, Hospital Nurse Staffing and PatientMortality, Nurse Burnout, and Job Dissatisfaction," Journal of the American Medical Association 288(Oct. 23/30, 2002): 1987-93.

[2] Baldrige National Quality Program, Health Care Criteria for Performance Excellence, National Institute ofStandards and Technology, United States Department of Commerce, 2003.

[3] Agency for Healthcare Research and Quality. National Healthcare Quality Report, prepublication copy, http://www.ahrq.gov/qual/nhqr03/nhqrsum03.htm.

[4] L. T. Kohn, J. M. Corrigan, and M. S. Donaldson, (Eds.). 1999. To Err Is Human: Building a Safer Health Care System.Institute of Medicine, published by National Academy of Sciences.

[5] E. C. Becher and M. R. Chassin, Hmproving the Quality of Health Care: Who Will Lead?" Health Affairs 20 (Sept./Oct. 2001): 164-179.

[6] K. Davis, S. C. Schoenbaum, K. S. Collins, K. Tenney, D. L. Hughes, and A. J. Audet, Room for Improvement: Patients Report on the Quality of Their Health Care, The Commonwealth Fund, 2002. Available at http://www.cmwf.org/programs/quality/davis_improve ment_534.pdf.

[7] Becher and Chassin cite research conducted from 1987 to 1997 , finding that roughly 30 percent of the care for acute conditions and approximately 20 percent of the care for chronic conditions were provided without appropriate clinical indications Such errors are also responsible for many injuries; extrapolating from studies of patients hospitalized in Colorado and Utah, Becher and Chassin estimate that errors cause injury to more than 300,000 patients each year. (Becher and Chassin).

[8] For example, a study at Brigham and Women's Hospital in Boston found that 6.5 percent of admitted patients suffer adverse drug events (ADEs), and 28 percent of those are preventable. Each preventable ADEcosts an estimated \$4,500, which amounts to \$2.8 million for this 700-bed hospital. When ComputerizedPhysician Order Entry (CPOE) was installed, ADEs dropped by nearly 80 percent, from 140 ADEs to 30per 1,000 inpatient days. CPOE saved the hospital from $\$ 5$ million

\section{Volume 5 Issue 4, April 2016}




\section{International Journal of Science and Research (IJSR) \\ ISSN (Online): 2319-7064 \\ Index Copernicus Value (2013): 6.14 | Impact Factor (2015): 6.391}

to $\$ 10$ million annually due to reducedADEs and increased efficiency in the use of drugs and tests. This compares with a one-time investment of $\$ 1.4$ million and $\$ 500,000$ in annual maintenance costs. (add citation?)

[9] For example, in 1998 only 55 percent of eligible Medicare patients with atrial fibrillation received the drug warfarin, which is highly effective in preventing stroke and other complications (American Health Quality Association (AHQA). 2000. A Measure of Quality: Improving Performance in American Health Care.October. AHQA: Washington, DC.)

[10] The Agency for Healthcare Research and Quality (AHRQ) estimates that expanded use of warfarin could reduce the number of strokes in patients with atrial fibrillation by 50 percent (from 80,000 to 40,000), thus saving an estimated 25,000 lives and $\$ 600$ million annually. D. B. Matcher et al., Medical treatment for stroke prevention," Annals of Internal Medicine 121 (July 1994): 54-55.

[11] Although a number of treatments-including appropriate and timely administration of aspirin, betablockers, ACE inhibitors, and reperfusion therapyhave been shown to reduce mortality rates significantly for heart attack victims, they are consistently underutilized. Greater use of ACE inhibitors has the potential to reduce mortality in elderly heart failure patients (80 percent of whom are ideal candidates for the drug) by 25 to 33 percent, potentially saving an estimated 36,000 lives each year and improving functional capacity and quality of life for heart failure patients. [Institute of Medicine (IOM). 2002. Minorities More Likely to Receive Lower-Quality Health Care, Regardless of Income and Insurance Coverage. National Academy of Sciences press release announcing release of new IOM study, Unequal Treatment: Confronting Racial and Ethnic Disparities in Health Care. The full press release and report are available at http://nationalacademies.org.]

[12] Influenza and pneumococcal disease are responsible for 20,000 to 40,000 deaths each year, primarily among the elderly. An estimated one-half $(10,000$ to 20,000) of these deaths could be eliminated through wider use of annual flu shots and one-time pneumococcal vaccinations (for the elderly). J. E. Wennberg, E. S. Fisher, and J. S. Skinner. - Gography and the Debate Over Medicare Reform," Health Affairs Web Exclusive, (Feb. 13, 2002): W96-W114.]31

[13] National Academy of Sciences, Minorities More Likely to Receive Lower-Quality Health Care, Regardless of Income and Insurance Coverage," 2002. Press release announcing new Institute of Medicine(IOM) study, Unequal Treatment: Confronting Racial and Ethnic Disparities in Health Care. The full press releaseandreport are available at http://nationalacademies.org.

[14] Agency for Healthcare Research and Quality, National Healthcare Disparities Report (prepublication copy). Available http://www.ahrq.gov/qual/nhdr03/nhdrsum03.htm.

[15] J. E. Wennberg, E. S. Fisher, and Skinner, 2002.

[16] Midwest Business Group Health (MBGH), Reducing the Costs of Poor-Quality Health Care Through
Responsible Purchasing Leadership.Chicago: MBGH, 2002.

[17]IOM, Crossing the Quality Chasm: A New Healthcare System for the 21st Century. Washington, D.C.: National Academy Press, 2002.

[18] We recruited for this study two hospitals with the best (lowest) HMSRs among the 30 hospitals scored by Jarman. One of these hospitals also had a low cost score (based on Jarman's adjusted reimbursement measure); the other hospital had a high cost score, related in part to its being in a high-cost medical and urban area (Boston). The two additional hospitals recruited for the study scored in the mid range (among the 30 hospitals) on Jarman's HMSR and cost measures; they were selected in part to achieve balance in terms of region, teaching status, size, etc.

[19]D. Kindig, Value Purchasers in Health Care: Pioneers or Don Quixotes? Milbank Memorial Fund, 2001.

[20]S. Mitchell and S. Shortell, - The Governance and Management of Effective Community Partnerships: A Typology for Research, Policy, and Practice," The Milbank Quarterly 78 (2): 241-89.

[21] E. Bradley, E. Holmboe, J. Matters, S. Roumanis, M. Radford, and H. Krumholz, -AQualitative Study of Increasing Beta-Blocker Use After Myocardial Infarction: Why Do Some Hospitals Succeed?" Journal of the American Medical Association 85 (May 23, 2001): 2604-11. 